\title{
Socialização em contextos de violência e desconfiança: reflexões sobre a obra República das Milícias - do esquadrão da morte à era Bolsonaro
}

\author{
Telmo Marcon* \\ Daniela dos Santos ${ }^{* *}$
}

A obra República das Milícias: do esquadrão da morta à era Bolsonaro, do jornalista Bruno Paes Manso, lançada em 2020 pela Editora Todavia (SP), tem a arte da capa de Pedro Inoue. Nas 302 páginas, o autor desenvolve oito capítulos e mais uma reflexão final com o título Ubuntu. Os capítulos estão assim organizados: 1) apenas um miliciano; 2) os elos entre o passado e o futuro; 3) as origens em Rio das Pedras e na Liga da Justiça; 4) fuzis, polícia, bicho; 5) facção e a guerra dos tronos; 6) Marielle e Marcelo; 7) as milícias $5 \mathrm{G}$ e o novo inimigo em comum; 8) Cruz, Ustra, Olavo e a ascensão do capitão.

A obra trata de um amplo conjunto de questões e personagens envolvidos nas tramas descritas, não apenas milicianos, mas, também, traficantes de drogas, grupos de extermínio não milicianos, policiais, bicheiros, setores do legislativo municipal, estadual e federal, personagens vinculados ao judiciário e setores do executivo de diferentes esferas da gestão pública. As ações desses múltiplos grupos organizados produzem relações de poder, dominação, silenciamento, assassinatos, chacinas, extorsões, controle de favelas e serviços básicos que deveriam ser função do Estado, legitimam ou censuram determinadas formas de vida social que resultam em novas formas de socialização extremamente precarizadas.

A presente resenha delimita uma questão que emerge da análise cuidadosa do autor: a socialização no contexto de relações sociais baseadas na subordinação, no medo e na desconfiança. Como pensar numa sociabilidade democrática e cidadã, onde as pessoas não têm as possibilidades efetivas de se constituírem, conviverem e se expressarem livre e democraticamente? É possível uma socialização humanizadora onde predomina o medo e a desconfiança no outro? Entende-se

\section{Recebida em: 17/05/2021 - Aprovada em: 17/05/2021 \\ http://dx.doi.org/10.5335/rep.v28i1.12586}

Doutor em História Social pela PUC-SP, com pós-doutorado em educação intercultural pela UFSC. Professor e pesquisador na Faed e no PPGEDU (mestrado e doutorado) da UPF. Orcid: http://orcid.org/0000-0002-9110-3210. E-mail: telmomarcon@gmail.com

* Doutoranda em Educação pelo PPGEDU da UPF. Professora na Faculdade de Ciências Econômicas, Administrativas e Contábeis da UPF. Orcid: https://orcid.org/0000-0001-9931-6352.E-mail: danielasantos@upf.br 
por socialização a apropriação e a vivência de normas e valores compartilhados, aceitos e reconhecidos numa determinada sociedade em seus diferentes contextos socioculturais. A socialização pode estar ancorada em princípios republicanos e cidadãos, mas, também pode ser precarizada. A obra em questão evidencia o quanto é precária a socialização de milhares de pessoas na grande Rio de Janeiro onde as milícias prosperaram de modo exponencial nas últimas duas décadas, gerando insegurança, violência, desconfiança, homicídios e chacinas. Nesse sentido, a obra descreve em detalhes um conjunto de realidades que afronta uma sociabilidade democrática e humanizadora.

A violência como prática social não é estranha à história da humanidade. Ela ganha, no entanto, diferentes formas e intensidades em cada contexto histórico. Bruno Paes Manso faz uma análise desse fenômeno na grande Rio de Janeiro, estabelecendo algumas breves conexões com São Paulo e outros estados. O que chama atenção é a privatização da cidade e o controle das pessoas, práticas que colidem com os avanços civilizatórios e republicanos. As transformações decorrentes dos processos de urbanização analisadas por Manso dão conta da emergência de novos sujeitos coletivos que se armam, estruturam-se e desenvolvem práticas de violência em defesa de interesses corporativos. Para tanto, fazem uso de armamento pesado, ameaçam, reprimem, torturam, assassinam, lincham, traficam, organizam segurança privada em troca de mensalidades e fidelidade.

Os grupos emergentes, especialmente milicianos, entram em confronto direto com outros grupos já existentes, resultando em disputas, tiroteios e mortes. Ao longo da obra há descrições de como os milicianos expandiram suas áreas de atuação e controle em várias regiões no rio de Janeiro e em setores estratégicos: monopolizando a venda de gás; gatonet; gatoluz; tráfico de armas; transporte clandestino em vãs; jogos de contravenção; jogo do bicho; controle na construção e venda de imóveis; cobrança de taxas para a segurança privada de moradores e empresas; assassinato de pessoas 'indesejáveis'; venda ilegal de cigarros; agiotagem; grilagem de terras (especialmente em éreas de preservação); grupos de extermínio; extorsão de dinheiro; pagamento de arrego, ou seja, taxas para a polícia não realizar abordagens e operações em determinados espaços etc. Quando milicianos entram em confronto com outros grupos, usando armamento pesado, o cidadão fica exposto a tiroteios, muitos morrem por balas perdidas, escolas e outros serviços públicos são fechados. O medo e a insegurança tomam conta das pessoas, produzindo um cotidiano extremamente incerto e precarizado. 
As milícias expandiram-se em contextos de fragilidades institucionais e de corrupção nas corporações oficiais que têm a finalidade de dar segurança ao cidadão. Não por acaso, muitos milicianos foram expulsos de suas corporações e criaram organizações paralelas. São exemplos bem conhecidos: Ronnie Lessa (acusado de assassinar a vereadora Marielle e seu motorista Anderson), Fabrício Queiroz e Adriano da Nóbrega (recentemente assassinado). Adriano passou a ganhar dinheiro como matador profissional, considerado um exímio atirador que tinha uma formação militar de alta qualidade (MANSO, 2020, p. 198). Dados mostram que em 2008 as milícias dominavam 171 áreas na grande Rio de Janeiro (2020, p. 88). Em 2008, foi criada a CPI das milícias, presidida pelo deputado Marcelo Freixo para apurar as ações de milicianos e as relações com o poder legislativo. A CPI foi concluída em 2008 e, desde então, até 2017, foram presos 1.310 milicianos acusados de múltiplos crimes (MANSO, 2020, p. 98).

A fala do miliciano Lobo, entrevistado por Manso e objeto de análise do primeiro capítulo da obra, ressalta a importância da nova ordem social que os milicianos ajudaram a instaurar: “... era melhor do que a vigente no passado, estabelecida por bandidos e pelo tráfico. A violência fundada dos paramilitares se justificava por ser um meio de defender os interesses dos cidadãos de bem contra a ameaça dos criminosos" (MANSO, 2020, p. 9). Chama atenção que entre os milicianos a corrupção e o roubo são inaceitáveis, enquanto os homicídios são naturalizados. Assassinar criminosos torna-se um ato heroico. O criminoso é o que rouba e essa condição é "intolerável e covarde" (MANSO, 2020, p. 13). Nesses casos, os assassinatos são justificados. Daí a grande quantidade de crimes cometidos por milicianos, bem planejados e executados, mas pouco investigados. A expressão "bandido bom é bandido morto" ganha, aqui, um sentido profundo. $\mathrm{O}$ miliciano sente-se autorizado a matar o bandido (traficante ou ladrão) para defender o cidadão de bem, ou seja, ele está do lado do bem. Esse discurso polarizado entre os do bem e os outros, é muito conhecido entre nós, especialmente desde a campanha presidencial de 2018.

Para executar bem o serviço de matar é fundamental a posse de equipamento de alta precisão para não deixar rastros do crime. É nesse contexto, que a milícia expandiu seus negócios, também, no contrabando de armas, especialmente do $\mathrm{Pa}$ raguai, visando a constituição de verdadeiros arsenais de guerra. Somente na casa do miliciano Ronnie Lessa, preso pelo assassinato de Marielle e seu motorista, Anderson, juntamente com o ex-PM Élcio de Queiroz, foi apreendido, em 2019, material suficiente para montar 117 fuzis (MANSO, 2020, p. 112). O livro relata situações de desvio de armas da polícia, contrabando de armas, partilha de espólios 
apreendidos em operações policiais. Em algumas operações da polícia, descreve Manso, parte das tropas sequer seguiram as ordens dos comandantes superiores e agiram por impulso próprio, gerando mais morte e sofrimento para pessoas e famílias. ${ }^{1}$

A expansão das milícias e outros grupos, à margem da lei, ocorre concomitantemente à corrupção de agentes e instituições públicas, incluindo setores do legislativo, do judiciário e do executivo municipal e estadual, bem como, do enfraquecimento do Estado na prestação de serviços básicos. Esses grupos organizados se expandem na mesma proporção em que o Estado encolhe, gerando um ambiente de insegurança, exploração, violência e de medo e, dessa forma, justificam suas ações. "Quando o Estado e a Justiça abrem mão de suas funções, a disputa é definida pela lei do mais forte" (MANSO, 2020, p. 293).

A sensação de uma aparente segurança gerada pela presença de milicianos permitiu a consolidação de um poder paralelo ao próprio Estado. Alguns agentes do Estado atuavam em diferentes espaços e funções ao mesmo tempo, ou seja, atuavam na corporação e também na segurança privada junto com milicianos. Assim, as milícias ampliaram seu poder de ação por dentro de espaços institucionalizados. Certas práticas foram facilitadas, na grande Rio de Janeiro, pela constituição geográfica da cidade, bairros e favelas, pelos complexos processos de urbanização e pela ausência de emprego e outras formas alternativas de sobrevivência. A obra de Manso ajuda a pensar a constituição dos territórios e seus processos socializadores. A cidade é um território em constante transformação. É o lugar onde as pessoas moram, trabalham, convivem, porém, o acesso às condições de uma vida digna não é para todos. O estudo de Rio das Pedras, analisada no capitulo terceiro, evidencia como os milicianos foram adentrando esse território, criando novas relações com a população, profundamente insegura e vítima da violência de traficantes e de outros grupos.

O preço que moradores pagam para ter a segurança privada de milicianos é alto, não somente monetariamente, mas, principalmente, social e cultural. As milícias aproveitaram-se da ausência do Estado criaram seus tentáculos, ganhando confiança da população e implementando práticas de controle e extorsão, impondo suas normas, legitimando a morte como um mal necessário para manter a ordem e a segurança da comunidade e banalizando a violência na certeza da impunidade. Daí a associação das milícias com a chamada banda 'podre' da polícia (MANSO, 2020, p. 31). 
Diante desse breve quadro, questiona-se como fica a socialização tanto nos espaços familiares e sociais, quanto no âmbito da escola? Se entendermos que a socialização tem de criar as condições para as pessoas se integrarem socialmente, educando-as para uma vida democrática, como ficam esses pressupostos em contextos de medo e insegurança? Como educar para a sensibilidade estética e a valorização do outro se as experiências são predominantemente de violência, medo e morte? A democracia exige confiança no outro. Como fica, então, a educação para uma vida democrática quando as relações sociais estão assentadas na desconfiança? Muitos autores problematizaram os desafios de uma educação democrática e cidadã, valorizando e reconhecendo o outro. A pesquisa feita por Manso evidencia o quão são precarizadas as formas de socialização no contexto analisado.

A história brasileira é permeada de violência e brutalidade, práticas fortalecidas durante a experiência escravocrata. A ditadura militar de 1964 a 1985 fortaleceu essa ideia que foi, posteriormente, disseminada em outros espaços. No capítulo oitavo da obra, Manso (2020, p. 257-287) analisa as raízes dessa tradição autoritária que foi radicalizada durante a ditadura de 1964 a 1985. Essa cultura não acaba com o fim da ditadura em 1985. Ao contrário, o autor mostra a sua continuidade em personagens conhecidos como do general Newton Cruz, de Olavo de Carvalho, o do coronel Brilhante Ustra até chegar a Jair Bolsonaro que ascende politicamente na medida em que o discurso miliciano é incorporado em sua pauta de campanha: combate aos corruptos e criminosos (inaceitáveis) e a defesa da violência para colocar ordem no país. Há, portanto, um conjunto de elementos discursivos e de práticas que justificam a violência e a morte de criminosos como valores. As milícias se estruturaram em cima desses pressupostos e disseminam em suas ações o medo, a morte e a desconfiança. A tese que defendem é que a violência é uma necessidade para instaurar a ordem social, ou seja, a violência é pedagógica e ensina como se comportar.

A lógica miliciana é que a violência produz ordem (MANSO, 2020, p. 13). Nesse sentido, é interessante a fala de Lobo, entrevistado por Manso (2020, p. 23), ao descrever as ações da milícia: "O segredo de ganhar a comunidade era fazer o que o Estado não conseguia fazer. Até escola particular pra criancinha especial o Betinho pagava. Quando o tráfico quis voltar, os moradores amavam tanto o pessoal que alguns até pediram armas para ficar atirando da janela nos traficantes”. Chama atenção, também, que operações policiais praticamente não ocorreram em áreas comandadas pelos milicianos. Onde a atua milícia a polícia praticamente não mata 
(2020, p. 244), ou seja, não faz operações, ao contrário das favelas onde entram em disputas os traficantes com os milicianos.

A pesquisa que resultou no livro teve como objetivo, segundo Manso (2020, p. 32), "compreender por que e como a sociedade vem produzindo esses comportamentos violentos e induzindo seus participantes a seguirem esses caminhos...". Assassinatos sem deixar rastros e a segurança privada com a cobrança por serviços (2020, p. 77), passou a dar mais dinheiro do que o tráfico, além de ser 'menos perigoso'. A ação miliciana, no entanto, não se limita às descritas acima. Passaram a influir e intervir na política partidária com a eleição de representes para os diferentes cargos eletivos: vereadores, deputados estadual e federal e ao senado, prefeitos, governador e presidente. Assim, o domínio dos milicianos implicou, também, a conquista de votos para candidatos indicados e apoiados pelas próprias milícias. As investigações sobre rachadinhas na Alerj envolvendo o atual senador Flávio Bolsonaro, quando ainda era deputado estadual, e as ações do miliciano Fabrício Queiroz, ajudam entender as vinculações entre a milícia e a representação política. Recursos advindos de práticas ilegais são 'lavados' de diferentes formas, entre as quais, investindo no setor imobiliário.

A tese desenvolvida por Manso é de que: a ausência do Estado em serviços básicos cria condições para a expansão de grupos privados que executam alguns desses serviços e, em contrapartida, exercem diferentes formas de domínio sobre as populações locais. Os processos que interferem na construção do território são fundamentais para a constituição de uma cidade que pode ser educadora ou geradora de mais desigualdades e discriminações. Nos processos educativos, o Estado se torna imprescindível, uma vez que detém o poder de administrar, regular, fiscalizar, executar programas e projetos sociais, defendendo os interesses comuns. Os contextos analisados por Manso, mostram as profundas cisões existentes nas cidades da grande Rio de Janeiro e os paradoxos e contradições estruturais que são agravados pela intervenção desses grupos corporativos que atuam em múltiplas frentes, a maioria delas ilegais como jogos de azar ou o jogo do bicho. O território é um produto, ou seja, uma construção social que pode servir de base para uma sociedade democrática e cidadã, mas também, como é o caso, constituir-se em espaço de exploração imobiliária e de controles políticos e paramilitares. Quando o Estado é ausente, o cidadão busca outras formas de suprir suas necessidades e é essa a realidade que oportunizou milicianos travestidos de 'empresários' a expandirem seus negócios, criando estruturas extremamente lucrativas e autossuficientes. O Estado, nessas circunstancias, acaba sendo "terceirizado ou leiloado", como 
diz Manso (2020, p. 77). As instituições que têm a obrigação legal de combater a violência e fortalecer o Estado de Direito ficam extremamente fragilizadas e as organizações paramilitares acabam se associando ao crime organizado. Atuam mais em conivência como o crime do que no seu enfrentamento. Basta ver a lentidão das investigações no caso Marielle e Anderson, assim como, no caso das rachadinhas na Assembleia Legislativa.

Como fica a formação das novas gerações, objeto fundamental das reflexões sobre socialização? Manso traz inúmeros elementos que ajudam a pensar como as novas gerações que estão se constituindo nesses contextos de violência terão dificuldades para experienciar práticas efetivamente democráticas. Muitas crianças são afastadas da escola por inúmeras razões; outras são inseridas em práticas vinculadas ao tráfico e ao crime; outras vivenciam desde muito cedo situações dramáticas. O relato de Reginaldo de quando era criança de 11 anos impressiona: "Com onze anos, eu tinha visto muita gente morta nas ruas. Com essa idade, também vi os primeiros homicídios acontecerem bem na minha frente" (2020, p. 148). Ele relata que num confronto entre grupos rivais um desses grupos ficou encurralado e foi feito refém pelos adversários.

Eles amarraram os braços e pescoços desses homens, como fazem na pesca do caranguejo, e levaram juntos, em fileira, para um lugar perto da minha casa. A embira (corda) foi puxada pelo chefe do grupo. Eu tinha acabado de chegar do trabalho. Ainda era criança. Estava sentado na soleira da minha porta, não tinha muro. Eu morava na subida do morro. O chefe do bando me viu e gritou: 'não sai daí, não, que é par você ver e aprender a ser homem'. $\mathrm{E}$ daí começou a chacina. Todos os doze foram mortos a pauladas, socos, pedradas e tiros calibre 22 (MANSO, 2020, p. 148).

Essa ideia de ver para aprender é parte da tese que o autor diz fazer parte do cotidiano desses grupos, entre os quais os milicianos, que entendem a violência como ação educativa. Como observa Manso (2020, p. 293):

O homicídio ensinaria aos demais o destino dos ladrões que ousavam desobedecer. Essa modalidade de assassinato, portanto, era vista como um antídoto ao roubo e ao tráfico de drogas, formas de violência consideradas covardes, desrespeitadoras das regras e geradoras de imprevisibilidade. Assassinatos, encarados desse ponto de vista, podem levar à ordem, que por sua vez traz segurança. Já o roubo e o tráfico são sinônimos de desordem, provocam medo e uma sensação de vulnerabilidade.

Essa hierarquia ocorre, também, em outras situações como o jogo do bicho: "o jogo é coisa querida, amada pelo povo. Tóxico é odiado" (2020, p. 164). Tóxico é coisa de traficante, enquanto o jogo do bicho é aceito. Em síntese, a obra traz um conjunto de provocações fundamentais para compreender determinados discursos que ga- 
nharam espaço nos últimos três anos. Tudo isso, no entanto, nos leva a questionar se é possível pensar a cidade como espaço educador e construtor de sociabilidade? Como pensar na garantia dos direitos sociais? Como o território pode propiciar uma socialização articulada à cidadania? Como pensar a Cidade enquanto espaço democrático e humanizador?

\section{Nota}

1 Não estranha o que ocorreu no dia 06 de maio de 2021 em Jacarezinho, Rio de Janeiro, quando uma ação da polícia resultou na morte de 29 pessoas, sendo 28 civis e um policial. Ainda não foram esclarecidas várias questões sobre as mortes, mas há indícios de crueldade, execuções e destruição de provas com a remoção de cadáveres. Após a leitura da obra de Manso (2020) é possível compreender melhor essas práticas e as possíveis disputas em pauta.

\section{Referência}

MANSO, Bruno Paes. República das Milícias: do esquadrão da morta à era Bolsonaro. São Paulo: Todavia, 2020. 